\title{
Developing an integrated, situated model for digital literacy in pre-service teacher education
}

\section{Ed Campbell}

School of Education, University of Cape Town, Cape Town, South Africa

cmpedu001@myuct.ac.za

https://orcid.org/0000-0002-6430-8202

\section{Rochelle Kapp}

School of Education, University of Cape Town, Cape Town, South Africa rochelle.kapp@uct.ac.za (corresponding)

https://orcid.org/0000-0001-7878-8721

(Received: 20 November 2019; accepted: 15 April 2020)

\section{Abstract}

In this article, we draw on the findings of a qualitative case study of the digital practices and perceptions of four pre-service English teachers in order to make the case for an integrated situated approach to digital literacy that takes identities into account. Our case study highlighted the ways in which the student teachers' perceptions of their own digital proficiency and of the affordances of the digital acted as barriers in their classrooms. Drawing on insights from New Literacy Studies and Authentic Learning theorists, we describe how we used these findings to inform subsequent curriculum design and pedagogy. We argue that in order for student teachers to engage meaningfully with the digital, they need to be provided with models and authentic tasks in the discipline that enable them to explore and then reflect on how to use the affordances of the digital as a tool for learning in their classrooms.

Keywords: English teacher education, digital literacy, new literacy studies, authentic learning, identity

\section{Introduction}

Over the past 15 years, numerous studies have shown that while technology is increasingly used in classrooms and often seen as the solution to educational problems, it is not used optimally in school classrooms, regardless of its affordances (Burnett, 2011; Hughes \& Robertson, 2013; Keating, Gardiner \& Rudd, 2009; Lim \& Khine, 2006; Prinsloo \& Sasman, 2015; ). Research by Lim and Khine (2006) concluded that despite its capability to transform teaching and learning, many teachers experience barriers when integrating technology and 
this serves to relegate its use to the periphery. And yet, relatively little research attention has been paid to pre-service teachers' perceptions of the digital and the effects thereof on practices.

In this article, we draw on the findings of a qualitative case study on the digital practices and perceptions of four pre-service English teachers who identified their digital proficiency as limited. Conducted by the first author, Campbell, at a South African University in 2015, the case study was motivated by our difficulties with trying to integrate digital literacy into a course on English methods for pre-service high school teachers during the previous year. The vastly different levels of digital proficiency within the class resulted in varying degrees of uptake and resistance by the student teachers when they were required to engage in tasks. While we attempted to address this through more explicit mediation, the introduction of designated digital literacy classes in the English Methods course seemed in some ways to reinforce an already existing digital divide in the class. Those students who were already technologically proficient and confident about their use of technology participated enthusiastically and designed interactive innovative lessons, while those who felt less able tended to avoid exploration of the affordances of unfamiliar territory. Interestingly, the barriers did not conform to conventional social categories such as social class, gender, educational background, or race and we realised that we needed to know much more about the perceptions and challenges experienced by those who struggled (see Campbell, 2016).

Research in South Africa by Czerniewicz and Brown (2013) has highlighted that, contrary to the generalised description of young people as "digital natives" (Prensky, 2001, p. 1), many South African students enter higher education as relative digital strangers. Our case study data supports this finding and further highlights the student teachers' perceptions of their own digital proficiency and of the affordances of the digital, as well as how these perceptions influence their practices. We outline the case study and its findings briefly to provide context and then describe how we used these insights and drew on New Literacy Studies and Authentic Learning principles to develop an integrated situated approach to pre-service digital literacy education that attempts to address existing barriers by taking student learning and identity into account.

\section{Conceptualising digital literacy}

Recent research has recognised the limitations of conceptualising the digital as a set of discrete skills that could be taught to teachers and that would consequently lead to better technology integration by them (Chigona, 2013; Ivala, Chigona, Condy, \& Gachago, 2013; Prinsloo \& Sasman, 2015;). Drawing on the work of post-structuralist theorists, in particular New Literacy Studies (Gee, 1990; Street, 1984), this research has contested the notion of digital proficiency as a set of decontextualised generic skills, redefining it as a literacy practice located within a particular discourse with accepted, characteristic ways of "sayingdoing-being-valuing-believing" (Gee, 1990, p. 142). 
The notion of literacy as social practice (Barton, Hamilton, \& Ivanič, 2000), expands the concept to include modes other than written language that are "multiple, multimodal, and multifaceted" (Alverman, Ruddell, \& Unrau, 2013, p. 1150). Martin's (2008) definition of digital literacy captures the inextricable connection between the digital and the context in which it is used.

[Digital literacy is] the awareness, attitude and ability of individuals to appropriately use digital tools and facilities to identify, access, manage, integrate, evaluate, analyse and synthesize digital resources, construct new knowledge, create media expressions, and communicate with others, in the context of specific life situations, in order to enable constructive social action; and to reflect upon this process. (p. 167)

This conceptualisation foregrounds practice or what teachers "do" (Barton et al., 2000, p. 6), that is, the "routinized" activities that constitute the norm in their classrooms and are considered meaningful and legitimate within their disciplines (Reckwitz, 2002, p. 250). In this view, teachers' digital practices reflect their underlying constructions of the digital and their understanding of its relationship to student learning and disciplinary content. In terms of this research, the conceptualisation of the digital as situated also enables a distinction between those literacy practices that are unconsciously acquired among peers within home discourses and those that characterise the more formally taught "secondary discourses" (Gee, 2008 , p. 143) that are integral to the ways of constructing knowledge in schooling and academic disciplines (Lankshear \& Knobel, 2011). As teacher educators, this shifts our thinking away from deficit constructions of literacy practices towards considering how to identify and harness the resources that pre-service teachers bring into the teacher education space, as well as how these may be connected to facilitate learning in their classrooms.

A significant body of research has described the ways in which teachers mimic the pedagogy that characterised their own schooling and the difficulties experienced by teacher education programmes in disrupting the investment in strongly held beliefs about classroom norms, appropriate pedagogy, and literacy practices that are the consequence of student teachers' own experiences of school discourses (Carrington \& Selva, 2010; Ryan, 2011). The preservice teacher education context is also challenging: student teachers are often intensely focussed on their own performance in the classroom rather than on student learning because they are aware of being constantly observed, monitored, and assessed (Fox, Campbell, \& Hargrove, 2011). These insights point to the inextricable connection between identity and learning (Christie, 2008; Pym \& Kapp, 2013; Walker, 2010). The extent to which teachers can connect and engage with newer literacy practices is likely to influence, in turn, their classroom practices and their constructions of learners and learning. An understanding of how student teachers perceive the role of the digital in their classrooms and position themselves in relation to the affordances of the digital is therefore essential to developing contextually appropriate pre-service teacher education. 


\section{The case study}

The case study was conducted over a period of five months. The participants were all females with undergraduate Arts and Social Science degrees and varying amounts of work experience. They were enrolled in a year-long Postgraduate Certificate in Education (PGCE) for high school pre-service teachers. The participants were taught by the authors in an English Methods course. Their ages ranged from mid-twenties to mid-thirties.

The data was gathered from four sources: (1) questionnaires providing background on participants' biographies, perceptions of and experiences with technology; (2) the participants' detailed lesson plans in which digital literacy had been integrated; (3) written reflections on these lesson plans, which included a rationale for their use of technology, as well as narratives of the difficulties experienced; and (4) a video-recorded, semi-structured focus group interview conducted after their first teaching practice, that focussed on the participants' perceptions of digital literacy, their decisions concerning the use of the digital in their lesson plans and experiences in the classroom, as well as their observations of mentor teachers' use of digital technology over a period of five weeks during their first teaching practice session.

The first author was responsible for the collection of data. While he co-taught the two digital literacy classes that preceded the data collection period, he was not involved in the assessment of the participants' assignments and did not engage in regular contact sessions nor in general communication with the students. His minimal involvement with the participants along with his familiarity with the participants' backgrounds placed him in an ideal position to collect data while still being distant enough from the participants to limit possible coercion, and power differentials coming into play.

After ethical approval for the study had been obtained and it had been presented to the class, four participants volunteered to participate. They were guaranteed anonymity and all names used in this article are pseudonyms. Although they came from diverse educational, race, and social class backgrounds and had varied degrees of digital proficiency and teaching experience, all four participants stated that they volunteered to participate in the project because they perceived their digital literacy as limited and believed that engagement with the research would benefit their understanding of how to integrate digital literacy into their future classes as practising teachers. The participants submitted their reflective writing regularly. Power differentials were further limited through the decision to conduct a focus group interview, rather than individual interviews, as well as the decision to adopt a semi-structured approach. The participants knew each other well and the atmosphere of camaraderie in the focus group enabled open engagement.

Using the research focus on participants' perceptions and practices as a guiding tool, as well as the NVIVO software system to organise the interview, lesson plan, questionnaire and reflection data, categories were assigned by clustering similar ideas and then assigning themes to the data as suggested by Ryan and Bernard (2003). While the use of multiple data 
sources over a period of time aimed to mitigate reactivity, we assumed that participants' perceptions would shift, especially after their experiences of teaching practice. We also assumed that while the first author was not involved in assessment of their work, his role as a digital literacy specialist would likely influence the participants' responses. However, our focus was on the meanings that the participants attributed to the lessons they produced and their "routinized" classroom digital practices (Reckwitz, 2002, p. 250). We were interested in how they viewed their teaching practice contexts, their use of resources, their experiences of the digital, and how they positioned themselves in relation to integration of digital literacy in their classrooms. Consequently, we focused on the "activity of identifying" (Sfard \& Prusak, 2005 , p. 17) in participants' reflective commentaries in relation to the actual lesson plans they produced. The patterns, contradictions, and silences produced by this analysis served as a resource for our subsequent curriculum development efforts.

\section{Pre-service teachers' perceptions and practices}

A crucial finding from the research was that, while the participants expressed deep insecurity about their digital proficiency in their reflective commentary and the interview, the background questionnaire showed that all four used a range of digital devices extensively in their informal contexts and had done so for years. The focus group discussion revealed that they measured their digital proficiency in terms of proficiency with specific devices and programmes. So, for example, the fact that their practice-teaching sites were equipped with electronic interactive white boards, often informally referred to in schools as SMART Boards, with which they were unfamiliar, caused considerable unease and was mentioned on numerous occasions during the focus group interview. This could be seen in a participant's comment that she was "quite upset" that an "expensive piece of equipment", the SMART Board, "was being used as a white screen" in her teaching practice school.

When the specific devices or programmes with which they were familiar were not used in their teaching practice contexts, the participants struggled to conceptualise how they would integrate digital literacy in their teaching. This finding points to a conflation of specific digital applications with digital literacy. It suggests that the teachers were focussed less on the use of the affordances of the digital for student learning and more on their own digital proficiency and insecurities about their technical digital skills.

Another important and related finding was that the participants seemed to conflate digital literacy practices with internet literacy and described their integration of digital literacy into lessons in terms of their use of the internet. They viewed the internet as a starting point for their lesson-planning and preparation, but simultaneously described it as "daunting" and "overwhelming." For example, one participant stated during the interview, "I think if you're using . . . if you're going online for academic purposes there . . . for me there's all the sudden information overload ... you don't know where [spoken with emphasis] to finally stop now . . . to use that information." In the focus group interview another participant described the tension between the usefulness and overwhelming nature of the internet, saying, 
I find personally that, and I think it translates the same evidently, that online there is so much information, and a lot of it is nonsense and a lot of it is stuff you could actually use, you know, depending on what you're looking for.

In essence, their lesson-planning focus was on searching, navigating, and evaluating already existing content on the internet. Participants spent many hours in this endeavour. While they believed that their internet searches would yield innovative and imaginative ways of presenting their lessons, an analysis of their lesson plans and reflective commentaries showed that their use of the internet tended to be confined to creating visual and/or audio hooks to engage learners, to provide an introduction to their lessons, and to connect to learners' prior knowledge. While these are all pedagogically sound uses of the internet, it was notable that the participants used the digital in presentation mode. Their lessons tended to reproduce and confirm rather than facilitate critical engagement and challenge their learners' assumptions and beliefs.

In general, it seemed that participants' fears about the learners' digital proficiency also played a role in their classroom practice. When they felt that their own digital practices were inferior to their learners, they limited learners' engagement in digital practices. For example, while the participants were all active seasoned users of social media in their personal lives, and their lesson plans revealed that they actively engaged their learners in discussions about social media usage in their learners' home discourses, they limited social media integration in their lesson plans to academic discussions about social media on topics such as "the dangers of social media" or "how to deal with cyberbullying." Apart from their discomfort with integrating social media as educational tools in their lesson plans, the interviews and reflective commentaries showed that participants wanted to limit their learners' digital literacy practices in the classroom, mostly because they thought that the learners might also be overwhelmed by the internet, or because they believed that the use of digital media might threaten their ability to exert control in their classes. In the focus group interview, a participant remarked,

I think that [searching the internet] could be difficult for students ... how much time do they spend looking at different sites for information? For us, that time they spent looking, they could have been just reading already what they had. . .

In response, another participant immediately connected learners' digital literacy practices to issues of control by saying,

We would be advancing, but then how do you . . . control so that you as the teacher are in control and ... 'yes, they have the poem or whatever text in front of them' and they are not doing something else.

These fears seemed directly related to well-documented teacher fears about loss of authority and power in the classroom (McCarty, 2006). What is significant is the ways in which participants' perceptions and practices restricted and confined the use of the digital as a resource for learning. It seemed that participants were also directly affected by school 
policies and practices. Generally, they witnessed very few models of integration of digital literacy in English classes during their teaching practice in schools. They also aligned themselves with localised school policies that banned the use of cell phones in schools.

\section{Developing an integrated, situated model}

Drawing on these findings, we re-designed the English Methods curriculum the following year in order to fully integrate digital literacy and address the digital divide by taking preservice teachers' digital literacy practices and their constructions of the digital into account. Our goal was to develop a model which would view their perceptions and digital practices as significant resources, and which would deliberately move them away from conceptualising the digital as a set of separate skills. New Literacy Studies provided an important theoretical lens for conceptualising the notion of the digital as situated literacy. Gee's (1990) notion that proficiency in a secondary discourse is attained through both unconscious acquisition and through explicit mediation to enable meta-awareness, was an important underlying framework.

Through the research process, we realised that in a context like the South African school classroom, where use of the digital is still optional and where its role in the curriculum is confined to functional, decontextualised genres (such as e-mail), we needed to find a way to motivate the teachers to see the value of the digital as a tool for learning in their disciplines. To do so, they would need opportunities to explore, reflect on, and experience the process through tasks drawn from their disciplines and would need to be exposed to models of excellent practice in the discipline. We found that Authentic Learning, as articulated by Herrington (2006) offers a task-based pedagogical approach with which to operationalise the concept of apprenticeship articulated by Gee (1990), through its emphasis on situated modelling, scaffolding, coaching, reflection, and authentic tasks. The emphasis on collaborative problem-solving, framed by Herrington (2006) as engagement in ill-defined tasks that can be approached from multiple points of entry, seemed particularly helpful since it enabled students to draw on and reflect on their diverse prior experiences, thus foregrounding the centrality of teaching and learning contexts and also building confidence.

In order to further aid pre-service teachers in drawing on the strength of their own experiences, our model for digital literacy in English teacher education places emphasis on lessons as "literacy events" (Barton et al., 2000, p. 3), rather than foregrounding specific digital skills. Barton and colleagues, foremost proponents of situated literacy approaches, define the literacy event as an interaction in which written language is central to its activities. They outline the elements of the literacy event as "settings, participants, artefacts and activities" (p. 17), which are constantly interacting. The digital is therefore viewed as an artefact embedded within the classroom context and highly contingent on other elements in the classroom - elements that are not necessarily viewed as digital per se. We argue that the situated literacy approach, coupled with Gee's (1990) notion of apprenticeship as guiding theory and Herrington's Authentic Learning (2006) as a method of operationalising these theories in practice, is an effective model for digital literacy in teacher education. The model 
has the potential to enable pre-service teachers to value their practices and to extend their resources in order to facilitate good teaching practice. Below, we provide a brief outline of examples of the ways in which we drew on this model to address student-teachers' deficit constructions of their own digital proficiency and their perception of the digital as an add-on separate skill.

Herrington (2006) has stressed that facilitating authentic learning is not just about providing examples from the real world. For meaningful learning to happen, there has to be a sense of purpose and motivation. An important move in the re-design of the curriculum was to shift away from labelling digital literacy a separate additional component of the curriculum and, rather, foregrounding its role in facilitating access to meaning in texts and facilitating critical language awareness, reiterating this through tasks. This approach enabled student teachers to realise the affordances of the digital in teaching textual analysis skills and to realise that they had existing skills and knowledge to offer. The approach inherently highlights the embeddedness and contingency of the digital among other elements within the literacy event (Barton et al., 2000). For example, while working on strategies for teaching a play, students worked collaboratively to assess and critically analyse the value of websites that could be used as resources to facilitate engagement with the play and help mediate Shakespearean language.

The task promoted vigorous discussion about what material was appropriate to use for teaching high school students, thus enabling the pre-service teachers to develop explicit criteria for evaluating websites that drew on their refined pre-reading and overview skills, as well as on their established practices with analysis of visuals, date of publications, context, relevance, authorship, their digital search strategies and their in-depth knowledge of the play and the difficulties of teaching Shakespeare. They were provided with additional information about how to assess the authenticity and credibility of websites. This exercise surfaced many of the pre-service teachers' anxieties surrounding the internet and enabled them to share search strategies and practices. Through collaborative authentic activities, they were able to see that many of their established intuitive search and critical analysis skills regarding the internet were valuable. This meant that they were provided with an explicit meta-language to describe and discuss these issues with their own learners, as well as with explicit guidance on how to hone their existing search skills.

We also used this task as an opportunity to discuss the potential affordances of using their learners' knowledge of the then dominating social media platform, Facebook, as a resource for the understanding of character, motivation, and plot in Othello. This provided an opportunity for student-teachers to address their own preconceptions about the role of social media and to address its potential as an educational tool in the classroom. This discussion was revisited after the student-teachers' first teaching practice by placing the negative constructions about the role of social media in a prescribed textbook comprehension exercise alongside a more positive article. The activity was used to stimulate debate about constructions of social media, but, importantly, also to develop lessons which stimulated the 
creation of higher order questions on analysing point of view in texts through close textual analysis, comparison, and writing tasks.

Another strategy was to draw on the pre-service teachers' knowledge of lesson-planning to enable them to reflect on the affordances of the digital in the context of a poetry lesson. In this instance, the lecturer's own use of the digital, particularly digital images obtained from Google Images, was assessed collaboratively by the class. Together they reflected on the affordances of digital resources that had been produced by students in previous years. These tasks reinforced the importance of purpose and audience in making choices about when and how to use technology. It highlighted the subjectivity of digital choices, and in so doing, addressed some of the affective issues raised by the case study.

Student teachers were then required to work collaboratively to produce a poetry lesson. All the groups used the same poem but were allocated different scenarios in terms of available digital resources. This meant that they had to think through the affordances of the digital for facilitating poetry teaching, as well as how to make optimal use of limited resources in underresourced teaching contexts. Using a scenario as part of an "activity" in the literacy event (Barton et al., 2000, p. 17) enabled multiple views on the limits and possibilities of the digital and also challenged the students not to use the digital as a substitute for critical engagement and/or only as a hook to engage their students. It also encouraged them to make creative use of low-tech resources such as drawing, gesture, and sound.

In order to facilitate meaningful acquisition of a situated notion of digital literacy practice, this combination of modelling, collaborative task-based activity, scaffolded reflection and discussion was reiterated throughout the year using content material that resonated with the school English curriculum. In addition to this, the pre-service teachers were encouraged to use and reflect on the classroom activities in their teaching practice. This recursive process of connecting theory to practice through dialogue and reflection is central to the process of developing meta-awareness about the role of the digital in facilitating learning. The approach also stressed critical engagement and explicit discussions were conducted on how to negotiate the digital divide in their classrooms in relation to particular tasks. This was done after the pre-service teachers had experienced different teaching practice contexts.

To reinforce this critical engagement and the multiple perspective approach, excellent school teachers from many contexts were invited to the English Methods contact sessions to share their digital literacy practices and the challenges of integration. We viewed two teachers bringing their learners in to the English Methods class to explain how they had benefitted from digitally-based, peer-learning in their English and history classes as a highlight of our study. Through this process we were also able to challenge the relatively conservative construction of literacy as being only about reading and writing in the school English curriculum, as well as the narrow construction of the digital as confined to the use of technology for decontextualised isolated tasks.

Whereas the activities and tasks during the year were fairly defined and scaffolded through prompt questions, coaching, and modelling, the final task for the year entailed completing an 
"ill-defined" digital task, defined by Herrington as "activities which have real-world relevance, and which present a single complex task to be completed over a sustained period of time" (2006, p. 4), which drew on the digital literacy, textual analysis, and reflection skills developed through the year. This task required the teachers to reflect on their development as teachers or develop a digital classroom resource. They could choose to work collaboratively, so that technically more advanced pre-service teachers could aid those who were not as advanced, in an attempt to compensate for the digital divide, even if just partially. Since this was a big task, they were encouraged to collaborate using social media and other digital communication resources (like WhatsApp and Google Classroom), so they could work on their videos outside class. The move from explicit, well-defined, scaffolded tasks to a more open-ended "ill-defined" task enabled pre-service teachers to apply their learning and receive peer feedback within the safe space of the English Methods class.

\section{Conclusion}

When we set out to integrate digital literacy into the English Methods class, we assumed a great deal about our pre-service teachers' investment in the digital and their grasp of its affordances for learning. The case study illustrated the importance of a focus on student teachers' interpretation of the role of the digital in their classrooms in relation to their own digital literacy practices. It illustrated how the participants' perceptions of their digital literacy competence and the strong boundaries they delineated between home and academic literacies played a role in the extent to which they used the digital in their classrooms, as well as in the ways in which they constrained their learners' practices. The participants conceptualised the digital as a relatively neutral add-on tool and used it as a means to engage their learners rather than as an intentional context-specific resource for learning.

The case study thus foregrounded the importance of taking teachers' identities and conceptions of the digital into account. It illustrated the need to fully integrate digital literacy into our own pedagogy rather than identify it as a discrete skill with the expectation that preservice teachers would figure out how to integrate it as a tool for learning into specific aspects of their pedagogy. Thus, our subsequent curriculum intervention focussed on scaffolding, explicit instruction, modelling, and collaborative learning using authentic tasks in order to create opportunities for exploration and reflection and to build meta-awareness (Gee, 1990; Herrington, 2006). While it is always difficult to quantify the success of curriculum change, our student evaluations have been overwhelmingly positive and our approach in subsequent years has yielded a much stronger take-up in development of wellintegrated creative digital resources as well as critical reflection on the affordances of the digital for learning. The combination of situated, explicit instruction combined with practice and reflection over time and in relation to experiences in schools has enabled the pre-service teachers to view the digital as a legitimate resource for learning and it has enabled a focus on the learners and their prior knowledge, thus challenging the rigid conceptions of the boundaries between school and home discourses. 


\section{Declaration of interest statement}

No potential conflict of interest was reported by the authors.

\section{Acknowledgement}

This work was supported by the National Research Fund (NRF) under Grant SFH13092346700; and the University of Cape Town Teaching Development Grant 07/11/2014.

\section{References}

Alverman, D. E., Unrau, N. J., \& Ruddell, R. B. (2013). Theoretical models and processes of reading. Newark, $\mathrm{NJ}$ : International Reading Association.

Barton, D., Hamilton, M., \& Ivanič, R. (2000). Situated literacies: Reading and writing in context. London, UK: Routledge.

Burnett, C. (2011). Pre-Service teachers' digital literacy practices: Exploring contingency in identity and digital literacy in and out of educational contexts. Language and Education, 25(5), 433-499. https://doi.org/ 10.1080/09500782.2011.584347.

Campbell, E. G. (2016). Pre-service teachers' practices and perceptions: Integrating digital literacy into English teacher education (Unpublished masters thesis). University of Cape Town, RSA. http://hdl.handle.net/11427/22765

Carrington, S., \& Selva, G. (2010). Critical reflection and transformative learning: Evidence in pre-service teachers' service-learning logs. Higher Education Research and Development, 29(1), 45-57. https://doi.org/ 10.1080/07294360903421384.

Chigona, A. (2013). Using multimedia technology to build a community of practice: Preservice Teachers' and digital storytelling in South Africa. International Journal of Education \& Development Using Information \& Communication Technology, 9(3), 17-27. https://files.eric.ed.gov/fulltext/EJ1071388.pdf

Christie, P. (2008). Changing schools in South Africa: Opening the doors of learning. Johannesburg, RSA: Heinemann.

Czerniewicz, L., \& Brown, C. (2013). The habitus of digital 'strangers' in higher education. British Journal of Educational Technology, 44(1), 44-53. https://doi.org/10.1111/j.1467-8535.2012.01281.x.

Fox, K. R., Campbell, M., \& Hargrove, T. (2011). Examining reflective practice: Insights from pre-service teachers, in-service teachers and faculty. Journal of Research in Education, 21(2), 37-54. https://eric.ed.gov/?id=EJ1098417 
Gee, J. P. (1990). Social linguistics and literacies: Ideology in discourses. London, UK: Routledge.

Gee, J. P. (2008). Social linguistics and literacies: Ideology in discourses (3rd ed.). London, UK: Routledge.

Herrington, J. (2006, October). Authentic e-learning in higher education: Design principles for authentic learning environments and tasks. Paper presented at the World Conference on e-learning in corporate, government, healthcare, and higher education, Honolulu, HI.

Hughes, J., \& Robertson, L. (2013). The power of digital literacy to transform and shape teacher identities. In H.H. Yang \& S. Wang (Eds.), Cases on online learning communities and beyond (pp. 68-87). Hershey, PA: Information Science Reference.

Ivala, E., Gachago, D., Condy, J., \& Chigona, A. (2013). Digital storytelling and reflection in higher education: A case of pre-service student teachers and their lecturers at a university of technology. Journal of Education and Training Studies, 2(1), 217-227. https://doi.org/ 10.11114/jets.v2i1.286.

Keating, A., Gardiner, C., \& Rudd, P. (2009). E-access, e-maturity, e-safety: A learner survey. https://www.researchgate.net/publication/242570324_E-access_Ematurity_E-safetyA_Learner_Survey

Lankshear, C., \& Knobel, M. (2011). New literacies (3rd ed.). Berkshire, UK: McGraw-Hill Education.

Lim, C. P., \& Khine, M. S. (2006). Managing teachers' barriers to ICT integration in Singapore schools. Journal of Technology and Teacher Education, 14(1), 97-125. https://bit.ly/2HghMup.

Martin, A. (2008). Digital literacy and the 'digital society.' In C. Lankshear, \& M. Knobel (Eds.), Digital Literacies (pp. 151-177). New York, NY: Peter Lang.

McCarty, T. L. (2006). Language, literacy, and power in schooling. New York, NY: Taylor \& Francis.

Prensky, M. (2001). Digital natives, digital immigrants Part 1. On the Horizon, 9(5), 1-6. https://bit.ly/2ySL1ib.

Prinsloo, M., \& Sasman, F. (2015). Literacy and language teaching and learning with interactive whiteboards in early schooling. TESOL Quarterly, 49(3), 533-544. https://doi.org/ 10.1002/tesq.237.

Pym, J., \& Kapp, R. (2013). Harnessing agency: Towards a learning model for undergraduate students. Studies in Higher Education, 38(2), 272-284. https://doi.org/ 10.1080/03075079.2011.582096. 
Reckwitz, A. (2002). Toward a theory of social practices: A development in culturalist theorizing. European Journal of Social Theory, 5(2), 243-263. https://doi.org/: $10.1177 / 13684310222225432$.

Ryan, G., \& Bernard, H. (2003). Techniques to identify themes. Field Methods, 15, 85-109. https://doi.org/ 10.1177/1525822X02239569.

Ryan, M. (2011). Improving reflective writing in higher education: A social semiotic perspective. Teaching in Higher Education, 16(1), 88-111. https://doi.org/10.1080/13562517.2010.507311.

Sfard, A., \& Prusak, A. (2005). Telling identities: In search of an analytic tool for investigating learning as a culturally shaped activity. Educational Researcher, 34(4), 14-22. https://doi.org/ 10.3102/0013189X034004014.

Street, B. V. (1984). Literacy in theory and practice. Cambridge, UK: Cambridge University Press.

Walker, M. (2010). Critical capability pedagogies and university education. Educational Philosophy and Theory, 42(8), 898-917. https://doi.org/ 10.1111/j.14695812.2007.00379.x. 